Texture of Crystalline Solids, 1981, Vol. 4, pp. 153-157

0390-7951/81/0403-0153\$06.50/0

(9) 1981 Gordon and Breach, Science Publishers, Inc.

Printed in the United States of America

\title{
A NOTE ON THE ROLLING TEXTURE OF NICKEL-IRON-NIOBIUM ALLOY
}

\author{
L. C. TAI and ZEN-JUE TAN \\ Central Iron and Steel Research Institute, \\ Beijing, China
}

(Received November 4, 1980)

\begin{abstract}
The nickel-iron-niobium alloy containing about $79 \% \mathrm{Ni}$, $8 \% \mathrm{Nb}$ and $13 \% \mathrm{Fe}$ in sheet form has been prepared and fabricated. The rolling texture of the alloy after cold reduction of 50 and $94 \%$ has been determined by using $\mathrm{X}$-ray counter diffractometer and the results are presented in pole figures. In comparison with $\mathrm{Ni}-\mathrm{Fe}-\mathrm{Mo}$, the results are discussed from a view of the difference of mechanical hardness between these two categories of alloys.
\end{abstract}

\section{INTRODUCTION}

The reversible $\mathrm{Ni}-\mathrm{Fe}$ alloys possessing high values of magnetic permeability at low magnetizing fields are generally known as permalloys. The highest value of initial permability occurs at about $78 \% \mathrm{Ni}$, the stoichiometric composition being related to the superstructure $\mathrm{Ni}_{3} \mathrm{Fe}$. With treatment at a critical range of temperatures below $600^{\circ} \mathrm{C}$ the change of magnetic properties is associated with the formation of superstructures.

The permalloys used in communication engineering are ternary Ni-Fe alloys containing Mo or quaternary alloys containing $\mathrm{Cu}$ and $M o$ or $\mathrm{Cu}$ and $\mathrm{Cr}$. In the recent design of head materials used in magnetic tape recording not solely the magnetic properties are required, but also the resistance to wear and insensitivity to stress are important factors to be considered.

The properties of the system of $\mathrm{Ni}-\mathrm{Fe}-\mathrm{Nb}$ have been investigated in detail by Masumoto and his co-workers. ${ }^{1}$ In our laboratory we have studied the physical properties of the $\mathrm{Ni}-\mathrm{Fe}-\mathrm{Nb}$ alloys. ${ }^{2}, 3$ It is found that adequate composition, fabrication and heat treatment of the material will yield optimum properties to meet the requirements in application as magnetic transducer materials. 
As cold rolling plays a significant role in the fabrication of the material, in connection with other work we have studied the rolling textures of some of the specimens upon which the present note is chiefly concerned.

\section{EXPERIMENTAL PROCEDURE}

The alloy ingots weighing about $25 \mathrm{~kg}$ were prepared in the usual way by melting in a vacuum induction furnace. The ingots were hot forged and rolled into slabs of $3 \mathrm{~mm}$ thickness. Samples for chemical analysis were taken from the forged bars, examples being given in Table I.

\section{TABLE I}

Chemical Compositions of $\mathrm{Ni}-\mathrm{Fe}-\mathrm{Nb}$ Alloy in Wt. $\frac{8}{6}$

\begin{tabular}{ccccc}
\hline \hline $\mathrm{Ni}$ & $\mathrm{Nb}$ & $\mathrm{C}$ & $\mathrm{Mn}$ & $\mathrm{Fe}$ \\
\hline 79.85 & 7.39 & 0.012 & 0.064 & balance \\
79.54 & 8.00 & 0.015 & 0.037 & balance \\
\hline
\end{tabular}

The slabs were cold rolled to a thickness of $1 \mathrm{~mm}$ after pickling. As the recrystallization temperature of the alloy is higher than that of the conventional permalloys, the intermediate anneal has to be carried out at a higher temperature. The material was then cold rolled to sheets of various thicknesses.

The textures of the cold rolled sheets after a reduction of $50 \%$ and a reduction of $94 \%$ were studied by using an X-ray counter diffractometer and the $\{111\}$ pole figures were plotted accordingly.

\section{EXPERIMENTAL RESULTS AND DISCUSSION}

We measured some of the physical properties of the specimens, the results being summarized in Table II. In this table, the physical parameters of Mo-permalloy are mainly chosen from the work of Borzorth ${ }^{4}$ except that the lattice constant was measured in our experiment with the specimens prepared in our laboratory. The specimens were annealed for 2 hours at $1000^{\circ} \mathrm{C}$ in dry hydrogen. With regard to the parameters of $\mathrm{Ni}-\mathrm{Fe}-\mathrm{Nb}$, the results were obtained in our experiments. It will be noted from the data that the value of mechanical hardness of $\mathrm{Ni}-\mathrm{Fe}-\mathrm{Nb}$ is higher than that of the Mo-permalloy.

The pole figures of the alloy after cold deformation are represented in Figures 1 and 2 . From the pole figures it is interesting to note that (110) [1 12 ] is the major component of the texture. This implies a [IIl] direction parallel to the transverse direction. The component (110) [112], however, shows a considerable spreading about its positions 
TABLE II

Physical Properties of $\mathrm{Ni}-\mathrm{Fe}-\mathrm{Nb}$ and Mo-Permalloy

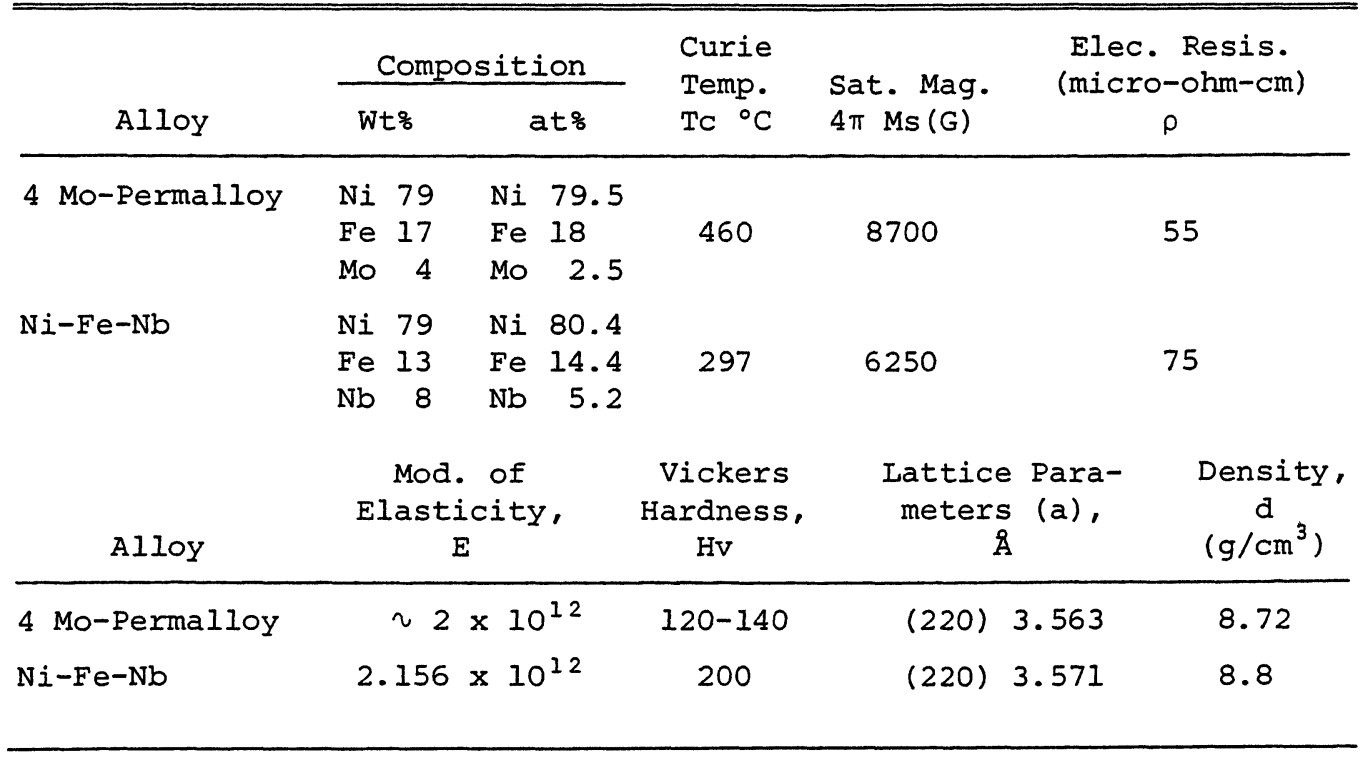

as indicated by Burgers and Verbraak ${ }^{5}$ for the f.c.c. metals in general.

In Figure 1 , the component $(1 \overline{1} 0)[001]$ and other weak component of high indices may be assigned to the orientations. After heavy rolling, with reference to Figure 2, the major component (110) [1I2] of the texture in the specimen seems more concentrated. The spreading about the position is not so great in the specimen which has undergone a reduction of $50 \%$

Recently some authors classified the rolling textures of the f.c.c. metals and alloys into the "copper type" and the "brass type." The texture of the Mo-permalloy after a cold reduction of $99 \%$ has been investigated by Koh. ${ }^{6}$ As we have pointed out that the $\mathrm{Ni}-\mathrm{Fe}-\mathrm{Nb}$ possesses higher mechanical hardness, so it seems reasonable to suppose that the rolling texture of $\mathrm{Ni}-\mathrm{Fe}-\mathrm{Nb}$ with the chemical compositions as above cited will near to the "brass type." From Figure 2, it will

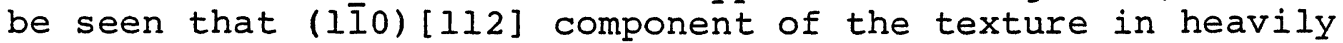
rolled alloy is a dominant texture. We consider that for f.c.C. alloys, like $\mathrm{Ni}-\mathrm{Fe}-\mathrm{Nb}$ which possesses a higher value of mechanical hardness, the spreading from the major component will not be so great as that of the soft material, Mopermalloy.

The phase diagram of the binary alloy of $\mathrm{Ni}-\mathrm{Nb}$ has been studied by Duerden and Hume-Rothery. ${ }^{7}$ When the concentration of $\mathrm{Nb}$ reached 4.2 ato, a precipitating phase will be formed in the alloy $\mathrm{Ni}-\mathrm{Nb}$ at room temperature. In our present investigation the concentration of $\mathrm{Nb}$ in the ternary alloy of $\mathrm{Ni}-\mathrm{Fe}-\mathrm{Nb}$ is 5.2 at\% and we have found no precipitating phase in the specimens. It shows that the solubility of $\mathrm{Nb}$ in $\mathrm{Ni}$ 


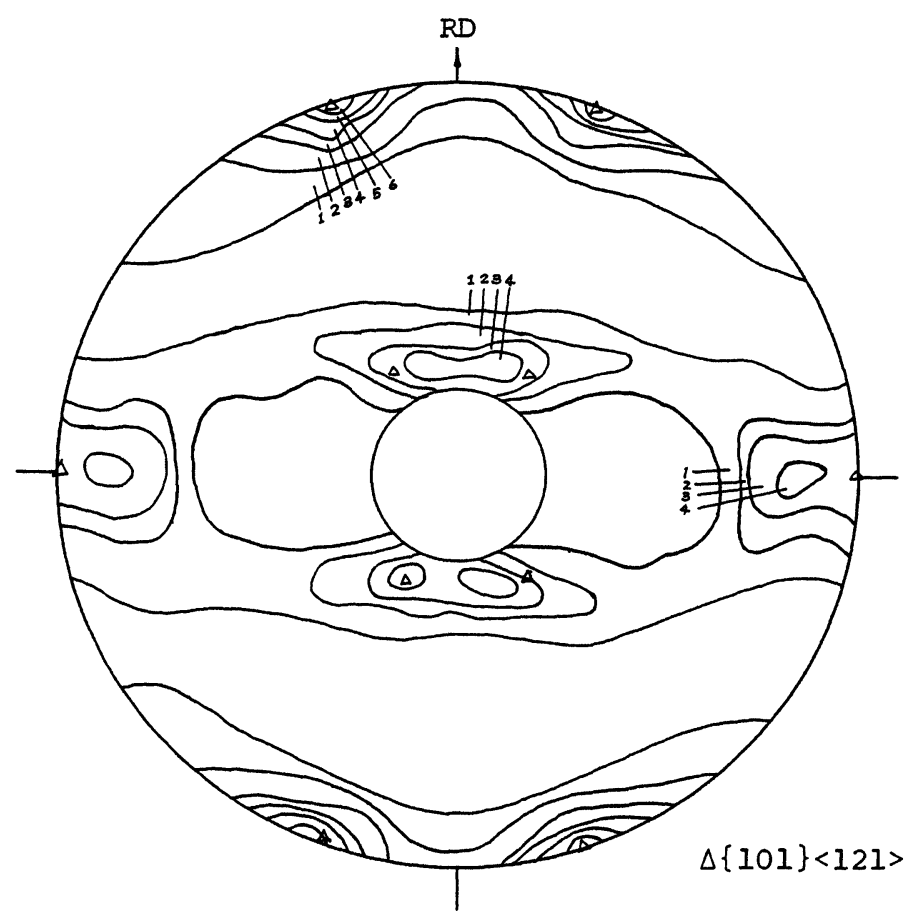

Figure 1. \{111\} Pole figure showing the rolling texture of $\mathrm{Ni}-\mathrm{Fe}-\mathrm{Nb}$ after a cold reduction of $50 \%$.

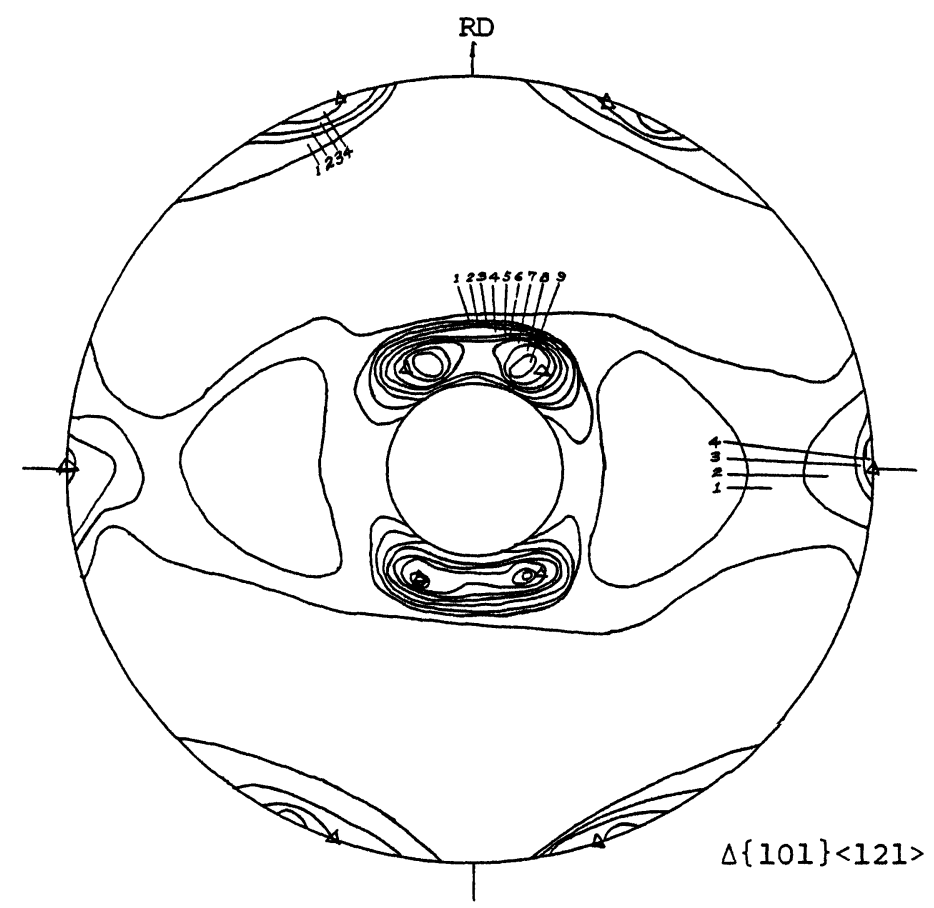

Figure 2. \{111\} Pole figure showing the rolling texture of $\mathrm{Ni}-\mathrm{Fe}-\mathrm{Nb}$ after a cold reduction of $94 \%$. 
may have been enlarged when $F e$ is added to the solution. By using the thin film technique in electron microscopy and the method of selected area in electron diffraction, it shows that both in Mo-permalloy and also in Ni-Fe-Nb after final anneal modulated structure is present in the specimens. The areas of the modulated structure are larger in $\mathrm{Ni}-\mathrm{Fe}-\mathrm{Nb}$ than in Mo-permalloy and the contrast is more in a state of preprecipitation to which the hardness of the metal may be attributed.

\section{SUMMARY}

1. The ternary alloy $\mathrm{Ni}-\mathrm{Fe}-\mathrm{Nb}$ possesses higher recrystallization temperature and higher mechanical hardness in comparison with the conventional technical Mo-permalloy.

2. The rolling texture of the alloy after a cold reduction of $50 \%$ and of $94 \%$ has been studied and it shows that the major component (110) [II2] is more concentrated in the heavily rolled specimens.

3. It is considered that the higher mechanical hardness of the alloy may yield a component of the texture not so spreading from its positions in the process of deformation.

\section{REFERENCES}

1. H. Masumoto et al., Trans. Jap. Inst. Metals, 13, 182 (1972).

2. I. C. Tai, J. J. Wang and D. H. Hou, Acta Phys. Sinica, 27, 260 (1978).

3. J. J. Wang, W. C. Xu, Z. H. Li and L. C. Tai, IEEE Trans. on Magnetics, Mag-10, 1572 (1979).

4. R. M. Bozorth, Ferromagnetism, Van Nostrand, 1951, p. 134.

5. W. G. Burgers and C. A. Verbraak, Acta Metall., 5, 765 (1957).

6. P. K. Koh, Trans. AIME, 215, 685 (1960); 221, 720 (1961).

7. I. J. Duerden and W. Hume-Rothery, J. Less-Common Metals, 11, 381 (1961). 